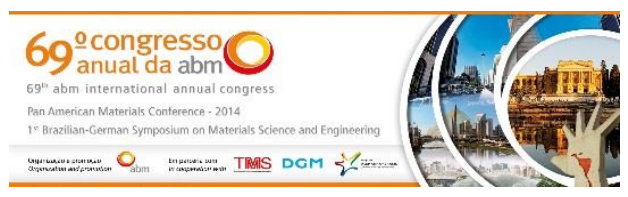

Tema: Mecânica de fratura e integridade estrutural

\title{
INVESTIGAÇÃO DA CONCENTRAÇÃO DE TENSÕES EM POÇO DE VISITA DE POLIETILENO POR EMISSÃO ACÚSTICA*
}

\section{Resumo}

Marcos Daniel Gouveia Filho' Ruy José Feijó Alves ${ }^{2}$ Jorge Sousa ${ }^{3}$

Enio Pontes de Deus ${ }^{4}$

Poço de visita (PV) é uma estrutura de redes coletoras de esgoto onde há a interligação dos fluxos de esgoto. Atualmente a maioria dos PVs em utilização é feito de anéis pré-moldados de concreto; concreto armado; e alvenaria (com blocos de concreto ou tijolos cerâmicos). Devido ao material de sua composição é facilmente sujeito a degradação, ao sofrer desgaste acabam liberando areia, acarretando vários problemas no equipamento de tratamento e no próprio tratamento do esgoto, além dos transtornos públicos ocasionado pela sua falha. Visando solucionar esses problemas, melhorar a qualidade e condições de tratamento de esgoto, busca-se implementar poços de visita produzidos de polietileno, material polimérico com características apreciáveis para essa finalidade, por exemplo seu caráter inerte, peso, resistência e vida útil. Como a estrutura é um protótipo, a influência de defeitos em sua integridade estrutural ainda não se encontra estabelecida. Neste trabalho investiga-se a concentração de tensões em sua estrutura e a influência de defeitos na concentração de tensões, através do método não destrutivo de emissão acústica e simulação computacional.

Palavras-chave: Poço de visita; Polietileno; Emissão acústica; Simulação computacional.

\section{INVESTIGATION OF STRESS CONCENTRATION IN MANHOLE OF POLYETHYLENE BY ACOUSTIC EMISSION}

\section{Abstract}

Manhole (PV) is a framework of sewage systems where there is interconnection flows of sewage. Currently the majority of PVs in use is made of precast concrete rings, reinforced concrete, and masonry (with concrete blocks or clay bricks). Due to its material composition is easily subject to degradation, to wear out eventually releasing sand, causing various problems in water treatment equipment and wastewater treatment itself beyond public disorders caused by its failure. Aiming to solve these problems, improve the quality and conditions of sewage treatment, seek to implement manholes made of polyethylene polymer material with appreciable characteristics for this purpose, for example, its inert character, weight, strength and life time. Since it the structure is a prototype, the influence of defects in its structural integrity is not yet established. This paper investigates the stress concentration in its structure and influence of defects on the stress concentration, through nondestructive method acoustic emission and computer simulation.

Keywords: Manhole; Polyethylene; Acoustic emission; Computational simulation.

1 Mestrando, Engenharia e Ciência dos Materiais, Laboratório de Mecânica da Fratura e de Materiais, Universidade Federal do Ceará (UFC), Fortaleza, Ceará, Brasil.

2 Graduando, Engenharia Metalúrgica e de Materiais, Laboratório de Mecânica da Fratura e Fadiga, UFC, Fortaleza, Ceará, Brasil.

3 Graduando, Engenharia Mecânica, Laboratório de Mecânica da Fratura e Fadiga, UFC, Fortaleza, Ceará, Brasil.

4 Doutor, Professor, Laboratório de Mecânica da Fratura e Fadiga, UFC, Fortaleza, Ceará, Brasil.

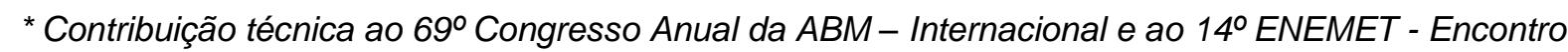
Nacional de Estudantes de Engenharia Metalúrgica, de Materiais e de Minas, 21 a 25 de julho de 2014, São Paulo, SP, Brasil. 


\section{INTRODUÇÃO}

A preservação do meio ambiente e da saúde pública é o papel principal da indústria do saneamento, através da prestação de serviços públicos de abastecimentos de água tratada e esgotamento sanitário. Estudos comprovam que os investimentos realizados em saneamento básico são quatro vezes mais efetivos que na saúde.

Durante a operação e a manutenção de redes coletoras de esgoto com os materiais convencionalmente utilizados, ocorrem falhas por desgaste prematuro das juntas de vedação ou danos no concreto, oriundos dos agentes agressivos presentes no meio. Desta forma, o solo que está submetido a esforços, fica susceptível a ser carreado para dentro dos poços de visita, entupindo os dutos coletores ligados ao mesmo, havendo o transbordamento de esgoto, e o abatimento da pavimentação próximo ao PV (com o surgimento de "buracos" na via pública). Os prejuízos são incalculáveis, pois além da poluição ambiental trazendo problemas de saúde pública, podem até causar acidentes com vítimas fatais no transito.

Não obstante, a areia carreada para dentro da rede coletora ainda causa graves problemas nas unidades de bombeamento das estações elevatórias e estações de tratamento de esgoto. Primeiro há o desgaste prematuro das peças do conjunto motor bomba, responsáveis por bombear o esgoto bruto para as unidades adjacentes e tratamento. Já na estação de tratamento há um declive de eficiência do tratamento do esgoto, com a presença de chuvas, as vazões aumentam significativamente, diluindo o esgoto a ser tratado e danificando os equipamentos de tratamento com a presença de areia.

O consumo mundial de materiais poliméricos vem em uma forte crescente de acordo com as descobertas e inovações tecnológicas na área. Ocasionando diversas aplicações específicas e substituição de outros materiais obtendo resultados satisfatórios ou melhores em desempenho, como em nosso caso. Quando comparamos, por exemplo, a resistência à abrasão do polietileno com concreto. (Figura 1)

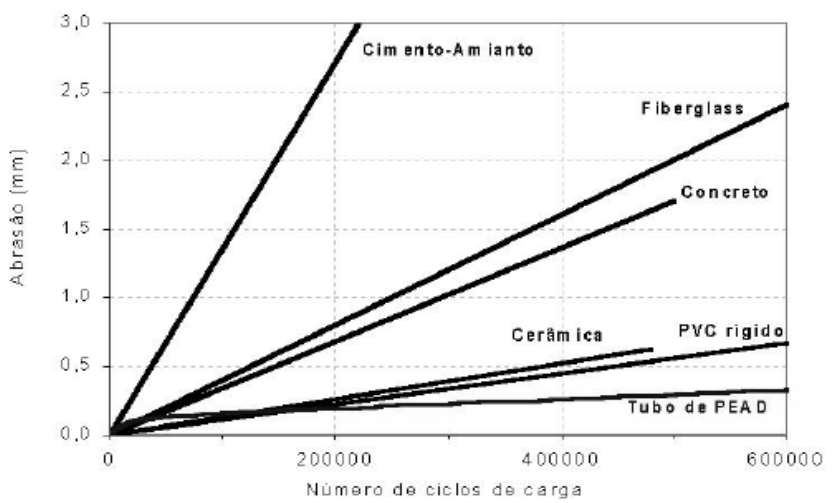

Figura 1 - Gráfico de abrasão por número de ciclos da carga (água com areia).

Fonte: Universidade de Darmstad Alemanha - (South German Plastics Centre in Würzburg).

Visando solucionar os problemas apresentados, melhorar a qualidade e condições de tratamento de esgoto, busca-se implementar poços de visita produzidos de polietileno, material polimérico com características apreciáveis para essa finalidade, como seu caráter inerte, peso, resistência e vida útil, tornando assim o polietileno um material com grande potencial para construção de poços de visita.

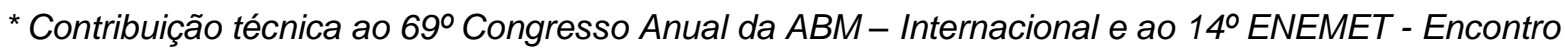
Nacional de Estudantes de Engenharia Metalúrgica, de Materiais e de Minas, 21 a 25 de julho de 2014, São Paulo, SP, Brasil.
} 


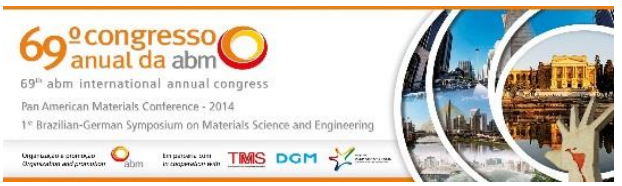

\subsection{Objetivo}

O ensaio não destrutivo de emissão acústica será realizado a fim de averiguar as regiões mais propícias a falhar perante solicitação mecânica, investigando as concentrações de tensão na estrutura do PV e influência de defeitos na concentração de tensão para garantir integridade estrutural do PV antes que seja implementado no sistema de esgoto para teste.

\subsection{Revisão Bibliográfica}

\subsubsection{Poço de visita}

Poço de Visita (PV) é uma estrutura integrante das redes coletoras de esgotos de grande importância, pois nele é onde há o encontro do fluxo de esgotos provenientes de diversas instalações que então são orientados e seguem para o posterior tratamento.

Atualmente a maioria dos PVs em utilização é feito de anéis pré-moldados de concreto; concreto armado; e alvenaria (com blocos de concreto ou tijolos cerâmicos). Devido ao material de sua composição é facilmente sujeito a degradação erosiva e corrosão, ao sofrer desgaste acabam liberando areia, acarretando vários problemas no equipamento de tratamento e no próprio tratamento do esgoto, além dos transtornos causados à sociedade e ao ambiente ocasionado pela sua falha.

O principal agente corrosivo e de degradação do material em redes coletoras de esgoto é o ácido sulfídrico, sua formação é explicada pela sequência a seguir:

- As bactérias redutoras de sulfatos necessitam de oxigênio para consumir a matéria orgânica existente na água do esgoto. Quando o oxigênio não está disponível, estes microrganismos o retiram dos íons sulfato ( $\mathrm{SO}_{4}{ }^{2-}$ ) disponíveis no meio aquoso deixando livres os íons sulfeto $\left(\mathrm{S}_{2}^{-}\right)$;

- A reação do sulfeto, com a água, resulta no gás sulfídrico $\mathrm{H}_{2} \mathrm{~S}$, conhecido pelo seu cheiro característico de ovo podre;

- O gás liberado é absorvido pelas partes superiores do coletor de concreto, sendo novamente oxidado e transformado em ácido sulfúrico $\left(\mathrm{H}_{2} \mathrm{SO}_{4}\right)$;

- $\mathrm{O} \mathrm{H}_{2} \mathrm{SO}_{4}$ ataca o concreto nas partes superiores do coletor, transformado o hidróxido de cálcio $\mathrm{Ca}(\mathrm{OH})_{2}$ do concreto em gesso $\left(\mathrm{CaSO}_{4} \cdot 2 \mathrm{H}_{2} \mathrm{O}\right)$.

Os ácidos citados se formam e atacam quimicamente as paredes dos tubos de concreto, danificando-os por processos corrosivos. Assim, da necessidade de materiais mais resistentes às reações específicas que ocorrem em efluentes sanitários, os materiais poliméricos despontaram e tornaram-se foco de estudo para esta área de aplicação.

\subsubsection{Polietileno}

O polietileno é um polímero semicristalino, cuja parte cristalina é constituída de moléculas regularmente organizadas dentro de lamelas com a conformação em zigzag. As lamelas são interconectadas por moléculas de interligação, as quais formam pontes intermoleculares que constituem as regiões amorfas. A estrutura formada cresce radialmente formando esferulitos. A estrutura cristalina típica do polietileno é a hexagonal ortorrômbica com os seguintes parâmetros de rede: $\mathrm{a}=0.791 \mathrm{~nm} ; \mathrm{b}=0.494 \mathrm{~nm} ; \mathrm{c}=0.255 \mathrm{~nm}$ [1].

A maioria das propriedades físicas, mecânicas e termodinâmicas dos polímeros semicristalinos depende do grau de cristalinidade e da morfologia das regiões 
cristalinas. Quanto maior a cristalinidade, mais elevadas são as propriedades de densidade, rigidez, estabilidade dimensional, resistência química, resistência à abrasão, temperatura de fusão, temperatura de transição vítrea, temperatura de utilização, etc. Por outro lado, reduzem-se as propriedades de resistência ao impacto, elongação na ruptura, claridade óptica, etc [2].

Dentre as diversas propriedades de um material, visando aplicação do polietileno em redes coletoras, tratamento e distribuição de água, destacam-se as seguintes propriedades:

- Leveza

- Flexibilidade

- Elevada resistência ao impacto

- Elevada Resistente à compressão

- Elevada Resistente à abrasão

- Atóxico

- Inércia química

- Impermeável

- Imunidade total a corrosões eletrolíticas e galvânicas

- Rugosidade baixíssima (coeficiente $C=150$ ) Hanzen-Williams

- Baixo coeficiente de atrito na parede interna do tubo (Manning de 0,010)

- Baixíssimo efeito de incrustação

- Elevada vida útil (mais de 50 anos)

\subsubsection{Emissão acústica}

Segundo Allevato e Ramos [3], emissão acústica são ondas elásticas transientes geradas pela emissão rápida de energia por fontes localizadas no interior do material [3]. Em contraste com a maioria dos métodos complementares de ensaios não destrutivos os sinais detectados de emissão acústica são gerados pelo objeto em teste, mediante a aplicação de um estímulo, detectando-se as descontinuidades durante o processo de degradação da integridade da estrutura [4]. Sua maior contribuição é proporcionar uma avaliação global do equipamento sob o enfoque da presença de descontinuidades comprometedoras da integridade estrutural do componente.

Emissão Acústica é o fenômeno que ocorre quando uma descontinuidade é submetida a uma solicitação térmica ou mecânica. Uma área portadora de defeitos é uma área de concentração de tensões, que uma vez estimulada, origina a liberação de ondas de tensão, na forma de energia propagando-se na pelo material em forma de ondas mecânicas transientes. A técnica consiste em captar esta perturbação no meio, através de transdutores piezoeléctricos instalados de forma estacionária nas regiões de interesse. Estes receptores passivos transformam a energia mecânica em energia elétrica, sendo os sinais arquivados para análise. Eventuais áreas portadoras de defeitos são localizas das através do estudo de cada forma de onda particular.

Instabilidades locais são desenvolvidas nas estruturas antes do colapso. Estas instabilidades podem se manifestar na forma de deformação plástica, iniciação e/ou propagação de trincas, bandas de deslizamento, etc.[4] As tensões desenvolvidas nas regiões que contém descontinuidades podem assumir valores superiores às tensões limites de escoamento em função dos concentradores de tensão. Nesta situação, a propagação das descontinuidades atua como fonte de sinais de emissão acústica.

Finalmente, um sinal ideal de emissão acústica pode ser descrito conforme a equação 1. Um sinal gerado segundo a equação 1 é apresentado na Figura2.

* Contribuição técnica ao 69 Congresso Anual da ABM - Internacional e ao 14º ENEMET - Encontro Nacional de Estudantes de Engenharia Metalúrgica, de Materiais e de Minas, 21 a 25 de julho de 2014, São Paulo, SP, Brasil. 


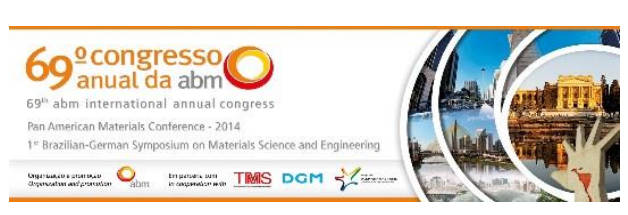

$$
V=V_{0} \cdot e^{(-B \cdot t) \operatorname{sen}(\omega \cdot t)}
$$

Equação 1

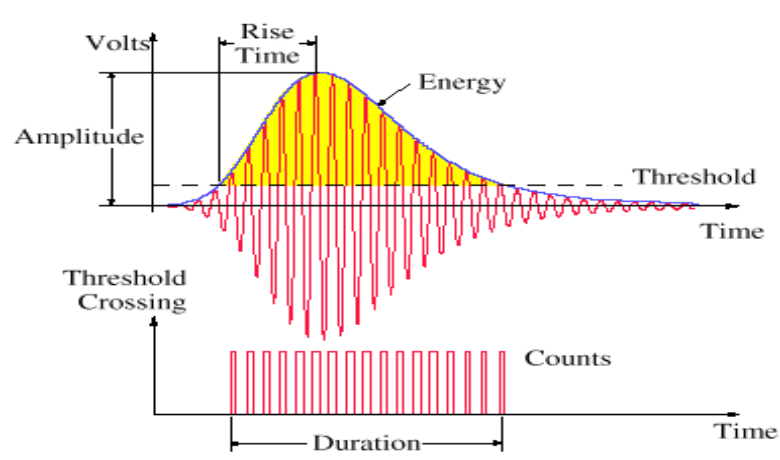

Figura 2 - Sinal de emissão acústica.

Para a análise dos sinais/ondas/hits de emissão acústica os principais parâmetros considerados, descritos pela Associação Brasileira de Normas Técnicas, são: [5]

Amplitude: é o maior pico de tensão atingido pelo sinal de emissão acústica e está relacionado à magnitude da fonte do evento. Expresso em decibéis ( $d B$ ). Contagem(counts): é o número de vezes que o sinal cruzou o limiar de referência. Duração(duration): é o intervalo de tempo entre a primeira e última vez que o sinal ultrapassa o limiar. Expresso em microssegundos ( $\mu \mathrm{s})$.

Tempo de subida(rise time): é o intervalo de tempo entre a primeira vez que o sinal cruza o limiar de referência e o momento em que o pico de amplitude é atingido. Expresso em microssegundos $(\mu \mathrm{s})$.

Energia(energy): É a medida da área retificada do sinal de emissão acústica.

\section{MATERIAIS E MÉTODOS}

\subsection{Amostras}

As amostras foram fabricadas pela empresa Plastsan Plásticos do Nordeste, através do processo de rotomoldagem e consistem em três PVs de polietileno.

\subsection{Simulação Computacional}

A partir do desenho técnico estrutural do protótipo, cedido pelo fabricante, gerou-se o modelo 3D do PV. A geração da malha e as simulações foram realizadas pelo software ANSYS 14.0. O elemento utilizado para formar a malha foi o elemento tetraédrico SOLID187 de 10 nós com três graus de liberdade cada um.

\subsection{Emissão Acústica}

Foi utilizado o sistema operacional SAMOS multichannel Acoustic Emission system, da Physical Acoustic Corporation, com três sensores R15I DN 46, DN 47 e DN 49, respectivamente. Utilizou-se também graxa de vedação de silicone para acoplar o sensor ao PV. O filtro escolhido, capaz de eliminar ruídos, foi de $30 \mathrm{~dB}$, comprimento do hit de $1 \mathrm{k}$ (1024 pontos), uma taxa de amostragem de $1 \mathrm{MSP} / \mathrm{s}\left(10^{6}\right.$ pontos/segundo) e pré-disparo de $256 \mu \mathrm{s}$.

* Contribuição técnica ao $69^{\circ}$ Congresso Anual da ABM - Internacional e ao 14 $E N E M E T$ - Encontro Nacional de Estudantes de Engenharia Metalúrgica, de Materiais e de Minas, 21 a 25 de julho de 2014, São Paulo, SP, Brasil. 


\subsection{Procedimento Experimental}

\subsubsection{Velocidade de propagação}

A velocidade de propagação da onda acústica no material é de fundamental importância para a correta discriminação e localização das fontes de emissão acústica. Por isso faz-se necessário o cálculo experimental para da velocidade de propagação do material. O ensaio segue metodologia semelhante à ASTM E976, na qual a fonte de emissão acústica é a energia liberada através da quebra de um grafite sobre a superfície da amostra, gerando uma onda mecânica que se propaga pelo material e é captada pelos sensores. Os sensores estão fixos e posicionados a distância (x) estabelecida em $0 \mathrm{~cm}, 12,5 \mathrm{~cm}$ e $17,5 \mathrm{~cm}$. A diferença de tempo entre a chegada da onda aos sensores revela a quantidade de tempo necessária para onda percorrer a distância determinada, assim pode-se calcular a velocidade de propagação da onda no material $\left(\mathrm{C}_{e}\right)$ através da equação 2. Para cada corpo de prova realizou-se cinco ensaios, utilizando o valor da média aritmética como resultado.

$$
C_{e}=\frac{x}{\Delta t}
$$

Equação 2

\subsubsection{Ensaio do Poço de Visita}

Nos ensaios de EA normalmente a fonte é o próprio material em teste, mediante a aplicação de um estímulo. Em nosso estudo a fonte será o próprio PV mediante um estimulo. O estimulo será produzido por uma breve aplicação de carga uniaxial de compressão de $350 \mathrm{kgf}$ sobre o PV. Depois de retirada a carga, o material tende a liberar a energia acumulada em forma de ondas de tensão, já que o ensaio ocorre no regime elástico, liberando assim uma quantidade de energia proporcional à tensão aplicada. Entretanto, descontinuidades agem como concentradores de tensão, modificando a distribuição de carga no material. Assim regiões com presença de descontinuidades acumulam e liberam uma maior quantidade de energia, portanto estão mais sujeitas a falhar.

\section{RESULTADOS E DISCUSSÃO}

\subsection{Simulação Computacional}

A malha gerada pelo software ANSYS 14.0, em função do elemento finito e da geometria do PV, conteve 462423 elementos e 861689 nós. Aplicando-se a carga compressiva de 350kgf distribuída sobre a "boca" do PV, observouse que na chaminé (região cilíndrica) tem-se uma pressão exercida de $448,4 \mathrm{kPa}$ e no cone temos $242,6 \mathrm{kPa}$. A figura 3 apresenta o modelo do PV, a malha, e por fim, tem-se uma indicação em vermelho (MAX) que indica o local de tensão máxima na parede interior do poço e que as regiões de transição de geometria, por exemplo, cilindro/cone ou cone/anel de sustentação, também concentram mais tensão.

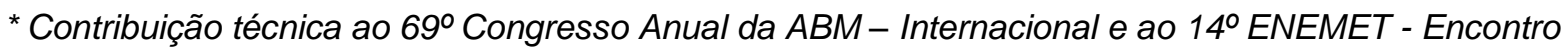
Nacional de Estudantes de Engenharia Metalúrgica, de Materiais e de Minas, 21 a 25 de julho de 2014, São Paulo, SP, Brasil.
} 


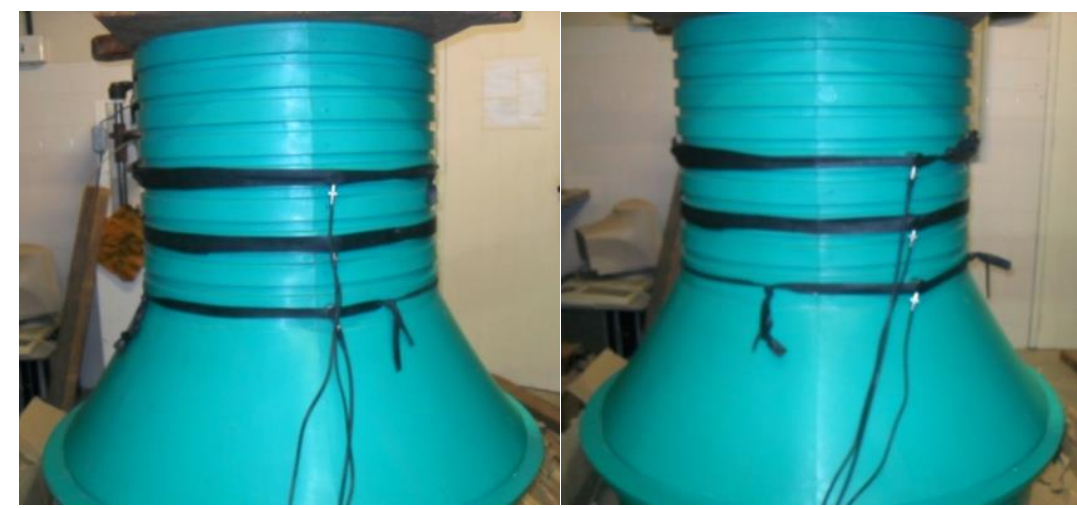

Figura 4 - Ensaio de emissão acústica na chaminé do PV na posição 1 e na posição 2 (+15cm).

Tabela 2 - Resultado do ensaio de emissão acústica para o PV 1.

\begin{tabular}{|c|c|c|c|c|c|c|}
\hline \multirow{2}{*}{ REGIÃO } & $\begin{array}{c}\text { Número } \\
\text { total de } \\
\text { ensaios }\end{array}$ & $\begin{array}{c}30-35 \\
\mathrm{~dB}\end{array}$ & $35-40 \mathrm{~dB}$ & $\begin{array}{c}40-45 \\
\mathrm{~dB}\end{array}$ & $>45 \mathrm{~dB}$ & $\begin{array}{c}\text { ENERGIA } \\
\text { (máximo) }\end{array}$ \\
\hline CILINDRO & 24 & 10641 & 2633 & 25 & 0 & 319 \\
\hline CONE & 16 & 11815 & 1599 & 38 & 11 & 512 \\
\hline
\end{tabular}

Após término da varredura do PV 1 e análise dos dados gerados por ele, foram adicionados 2 defeitos circulares passantes sendo um na região cilíndrica e um na região cônica, (Figura 5) com dimensões de $18 \mathrm{~mm}$ e $19 \mathrm{~mm}$ respectivamente. $\mathrm{Na}$ sequência retomaram-se os ensaios de missão acústica seguindo a mesma estratégia. Os resultados são apresentados na Tabela 3.

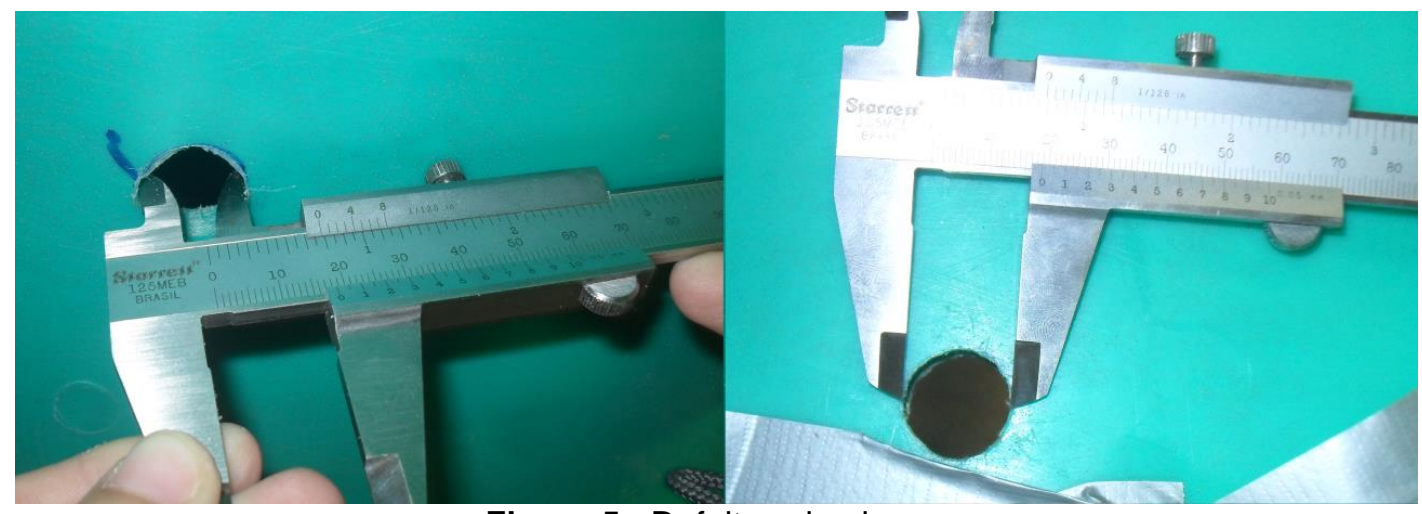

Figura 5 - Defeitos circulares

Tabela 3 - Resultado do ensaio de emissão acústica pra o PV 1 com defeito.

\begin{tabular}{|c|c|c|c|c|c|c|}
\hline \multirow{2}{*}{ REGIÃO } & $\begin{array}{c}\text { Número } \\
\text { total de } \\
\text { ensaios }\end{array}$ & $\begin{array}{c}30-35 \\
\mathrm{~dB}\end{array}$ & $35-40 \mathrm{~dB}$ & $\begin{array}{c}40-45 \\
\mathrm{~dB}\end{array}$ & $>45 \mathrm{~dB}$ & $\begin{array}{c}\text { ENERGIA } \\
\text { (máximo) }\end{array}$ \\
\hline CILINDRO & 24 & 14005 & 3524 & 399 & 59 & 4064 \\
\hline CONE & 16 & 17334 & 3724 & 821 & 81 & 8212 \\
\hline
\end{tabular}

O resultado dos ensaios de emissão acústica no PV $1 \mathrm{com}$ a presença do defeito mostra que houve um aumento significativo nos hits de uma maneira geral, assim como da máxima energia detectada nas regiões próximas aos defeitos, de acordo com o esperado. Na região em torno dos defeitos realizou-se ensaios para localização da fonte de emissão acústica utilizando o método de triangularização dos sensores, descrito por Miller, 1987. O método mostrou-se muito eficiente, localizando corretamente a posição dos defeitos.

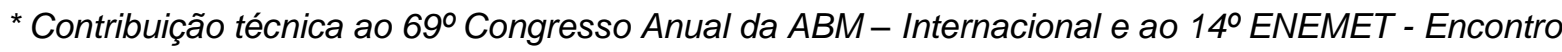
Nacional de Estudantes de Engenharia Metalúrgica, de Materiais e de Minas, 21 a 25 de julho de 2014, São Paulo, SP, Brasil. 
Dando continuidade foi ensaiado o PV 2. Os resultados estão apresentados na Tabela 4. Na parte cilíndrica não houve nada fora do comum, mas na parte cônica é percebido um número significativo de sinais de alta amplitude e também um alto valor de energia, como se pode observar.

Tabela 4 - Resultado para o ensaio de emissão acústica no PV 2.

\begin{tabular}{|c|c|c|c|c|c|c|}
\multirow{2}{*}{ REGIÃO } & $\begin{array}{c}\text { Número } \\
\text { total de } \\
\text { ensaios }\end{array}$ & $\begin{array}{c}30-35 \\
\mathrm{~dB}\end{array}$ & $35-40 \mathrm{~dB}$ & $\begin{array}{c}40-45 \\
\mathrm{~dB}\end{array}$ & $>45 \mathrm{~dB}$ & $\begin{array}{c}\text { ENERGIA } \\
\text { (máximo) }\end{array}$ \\
\hline CILINDRO & 24 & 11206 & 1774 & 31 & 0 & 421 \\
\hline CONE & 16 & 14116 & 2948 & 513 & 46 & 5283 \\
\hline
\end{tabular}

Para tentar entender a ocorrência desses sinais e/ou localizar sua origem, foi aplicado o método da triangularização para averiguação das regiões mais ativas acusticamente. A maioria das tentativas foi mal sucedida, pois o tempo de chegada dos sinais aos sensores não apresentavam regularidade, mas em uma região examinada o método foi eficaz, resultando na descoberta de uma inclusão metálica. (Figura 6a) Nas demais regiões a única indicação houve foi de que quanto próximo ao anel de sustentação maior era a amplitude e energia dos sinais captados. (Figura 6b) Então iniciou-se uma nova etapa visando analisar somente o anel de sustentação, com distância uniforme entre os sensores de 15 centímetros.
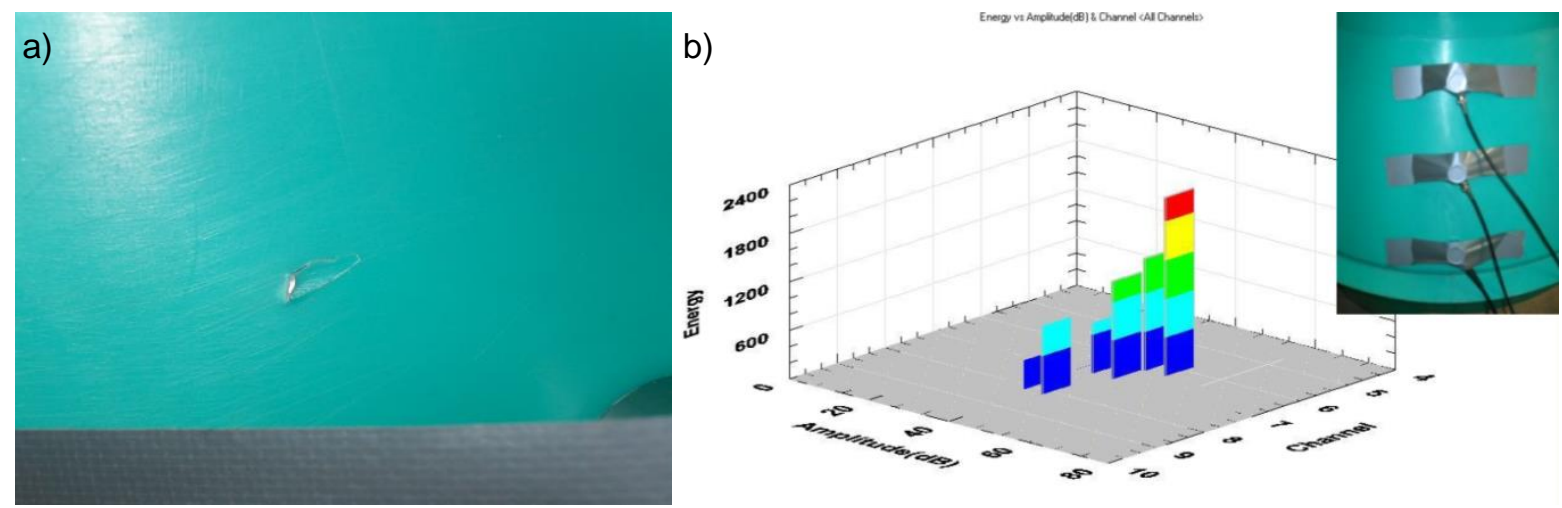

Figura 6 - a) Inclusão metálica localizada no PV 2. b) Sinal gerado na região cônica PV2.

Os resultados dessa nova etapa são apresentados na Tabela 5, mostrando que o anel de sustentação é a região que mais concentra tensões do PV 2, ou seja, uma região crítica e mais suscetível a falhar por solicitações mecânicas.

Tabela 5 - Resultado do ensaio de emissão acústica feito no anel de sustentação do PV 2.

\begin{tabular}{|c|c|c|c|c|c|c|}
\hline REGIÃO & $\begin{array}{c}\text { Número } \\
\text { total de } \\
\text { ensaios }\end{array}$ & $\begin{array}{c}30-35 \\
\mathrm{~dB}\end{array}$ & $35-40 \mathrm{~dB}$ & $\begin{array}{c}40-45 \\
\mathrm{~dB}\end{array}$ & $>45 \mathrm{~dB}$ & $\begin{array}{c}\text { ENERGIA } \\
\text { (máximo) }\end{array}$ \\
\hline ANEL & 6 & 3398 & 1655 & 253 & 113 & 8976 \\
\hline
\end{tabular}

Após análise dos resultados decidiu-se averiguar a estrutura interna do PV 2, pois o anel de sustentação apresentou um gradiente de energia. $O$ resultado foi "surpreendente", porém em acordo à emissão acústica, pois o mesmo apresentou grande variação de profundidade nas regiões internas do anel de sustentação. As regiões internas foram numeradas e medidas. (Figuras 7 e Tabela 6)

\footnotetext{
* Contribuição técnica ao $69^{\circ}$ Congresso Anual da ABM - Internacional e ao 14을 ENEMET - Encontro Nacional de Estudantes de Engenharia Metalúrgica, de Materiais e de Minas, 21 a 25 de julho de 2014, São Paulo, SP, Brasil.
} 


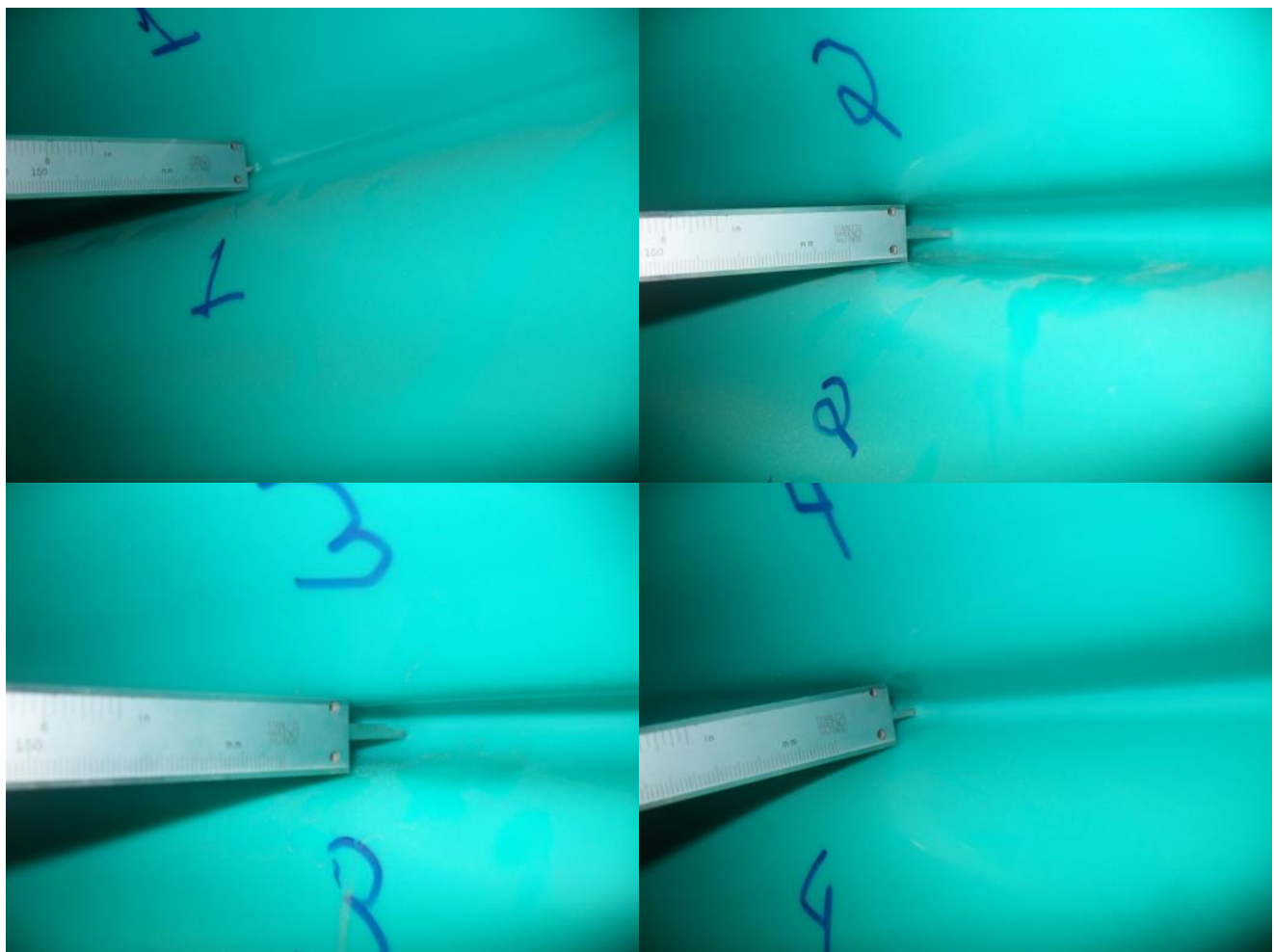

Figura 7 - Região 4 interna do anel de sustentação do PV 2.

Tabela 6 - Medidas das regiões internas do anel de sustentação do PV 2.

\begin{tabular}{|c|c|c|c|c|}
\hline $\begin{array}{c}\text { REGIÄO } \\
\text { INTERNA }\end{array}$ & 1 & 2 & 3 & 4 \\
\hline $\begin{array}{c}\text { PROFUNDIDADE } \\
(\mathrm{mm})\end{array}$ & 5,5 & 18,5 & 23 & 11 \\
\hline
\end{tabular}

A variação de profundidade das regiões internas do anel de sustentação (Figura 8) implica na variação da espessura da parede do mesmo, gerando um gradiente de tensão. Este fato resulta numa maior concentração de tensão na região com parede mais fina, ou seja, mais frágil, tornando ainda mais crítica essa região. A medida está de acordo com o ensaio de emissão acústica que caracterizou a região, correspondente a região interna 3 , como região acusticamente mais ativa.

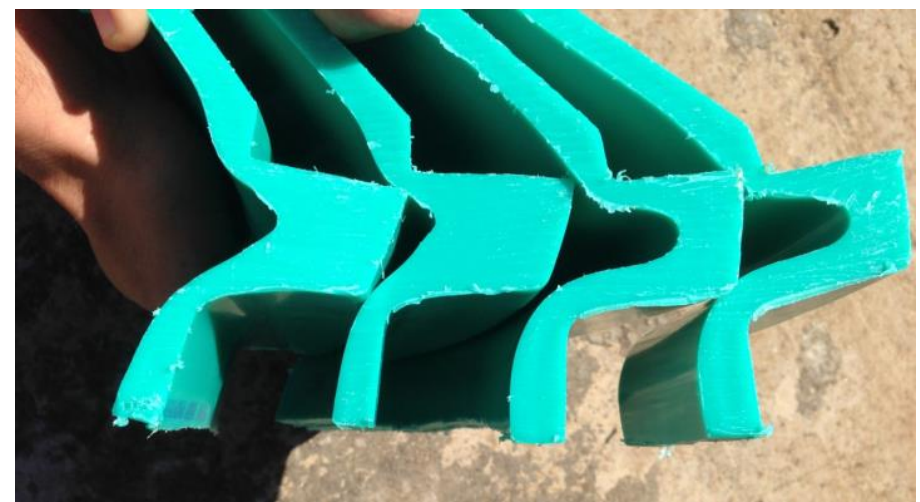

Figura 8 - Comparação entre a profundidade das regiões internas dos anel de sustentação do PV 2.

$\mathrm{Na}$ sequência foi ensaiado o PV 3 averiguando as regiões cilíndrica, cônica e do anel de sustentação. Realizando a medição das regiões internas do anel de sustentação. Resultados apresentados nas Tabelas 7 e 8. 
Tabela 7 - Medidas das regiões internas do anel de sustentação do PV 3.

\begin{tabular}{|c|c|c|c|c|}
\hline $\begin{array}{c}\text { REGIÃO } \\
\text { INTERNA }\end{array}$ & 1 & 2 & 3 & 4 \\
\hline $\begin{array}{c}\text { PROFUNDIDADE } \\
(\mathrm{mm})\end{array}$ & 4,5 & 13,5 & 15 & 8 \\
\hline
\end{tabular}

Tabela 8 - Resultado dos ensaios de emissão acústica no PV 3.

\begin{tabular}{|c|c|c|c|c|c|c|}
\hline \multirow{2}{*}{ REGIÃO } & \multirow{2}{*}{$\begin{array}{l}\text { Número } \\
\text { total de } \\
\text { ensaios }\end{array}$} & \multicolumn{5}{|c|}{ Número de hits por Amplitude } \\
\hline & & $\begin{array}{c}30-35 \\
\mathrm{~dB}\end{array}$ & $35-40 \mathrm{~dB}$ & $\begin{array}{c}40-45 \\
\mathrm{~dB}\end{array}$ & $>45 \mathrm{~dB}$ & $\begin{array}{l}\text { ENERGIA } \\
\text { (máximo) }\end{array}$ \\
\hline CILÍNDRO & 24 & 11422 & 1672 & 19 & 0 & 319 \\
\hline CONE & 16 & 9791 & 1650 & 22 & 4 & 451 \\
\hline ANEL & 6 & 2008 & 1105 & 131 & 32 & 3777 \\
\hline
\end{tabular}

Observa-se nos resultados que o PV 3 se comportou de forma semelhante aos outros quanto a região cilíndrica, a região cônica apresentou menor atividade acústica quando comparada aos outros, assim como o anel de sustentação, apesar de também haver variação de profundidade da região interna à ele. Para fins de comparação mediu-se a região interna do anel de sustentação do PV 1. (Tabela 9)

Tabela 9 - Medidas das regiões internas do anel de sustentação do PV 1.

\begin{tabular}{|c|c|c|c|c|}
\hline $\begin{array}{c}\text { REGIÃO } \\
\text { INTERNA }\end{array}$ & 1 & 2 & 3 & 4 \\
\hline $\begin{array}{c}\text { PROFUNDIDADE } \\
(\mathrm{mm})\end{array}$ & 5 & 13 & 15 & 7,5 \\
\hline
\end{tabular}

Para representação do resultado foram feitas novas simulações computacionais. Uma levando em conta apenas a cavidade interna ao anel de sustentação de $23 \mathrm{~mm}$ e outra os defeitos circulares e uma cavidade interna ao anel de sustentação de $15 \mathrm{~mm}$. Os resultados são apresentados a seguir: (Figuras 9 e 10).

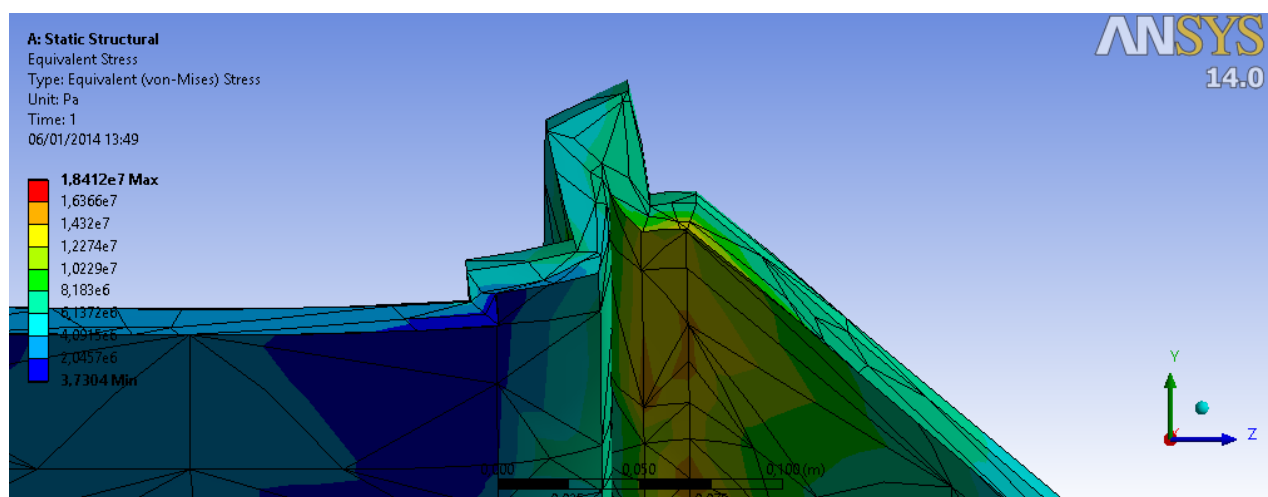

Figura 9 - Simulação do PV contendo apenas a cavidade interna do anel de sustentação de $23 \mathrm{~mm}$.

Pode-se observar que um PV apenas com cavidade de $23 \mathrm{~mm}$ na região interna ao anel de sustentação, concentra mais tensão que um PV com os dois defeitos e uma cavidade interna ao anel de sustentação de $15 \mathrm{~mm}$.

* Contribuição técnica ao 69ํㅡㄹ Congresso Anual da ABM - Internacional e ao 14ํㅡㄹ ENEMET - Encontro Nacional de Estudantes de Engenharia Metalúrgica, de Materiais e de Minas, 21 a 25 de julho de 2014, São Paulo, SP, Brasil. 

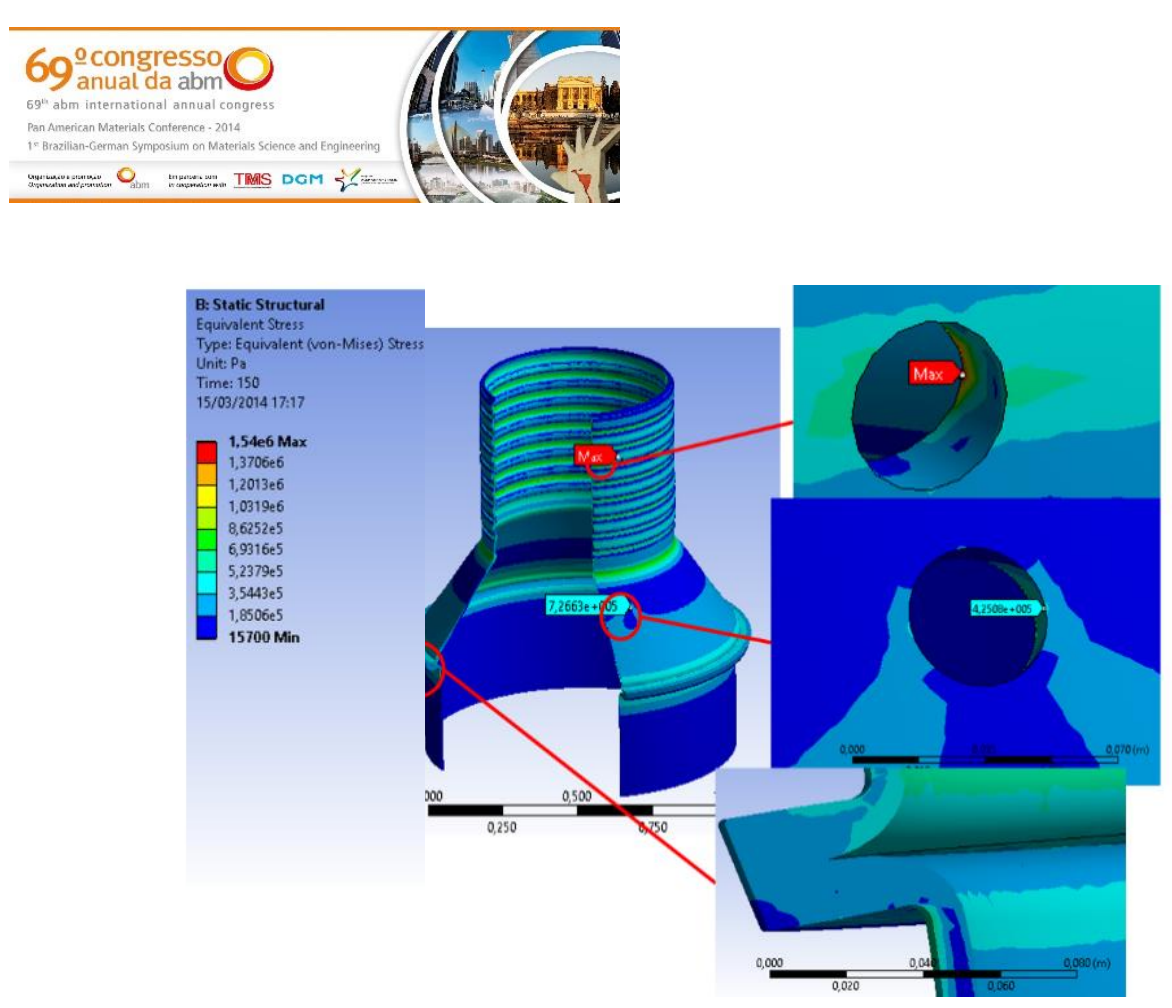

Figura 10 - Simulação do PV contendo defeitos e cavidade interna do anel de sustentação de 15mm.

\section{CONCLUSÃO}

Conclui-se que o método de emissão acústica é de fato eficaz quanto à avaliação de tensões e concentradores de tensão em um PV de polietileno. Que o método de localização da fonte de emissão acústica para localizar descontinuidades do material também é bem sucedido. Conclui-se ainda que o PV 3 apresenta concentradores de tensão de menor magnitude podendo ser considerado integro estruturalmente quando comparado aos outros e está pronto para prosseguir na fase de testes quanto à protótipo, podendo inclusive ser implementado para teste real, no que diz respeito a sua integridade estrutural.

\section{Agradecimentos}

Agradeço a empresa Plastisan Plásticos do Nordeste por disponibilizar o material de estudo e pelo suporte prestado para a realização deste trabalho e ao órgão de fomento CNPq por financiar e tornar esta pesquisa possível.

\section{REFERENCIA BIBLIOGRÁFICA}

1 Callister Jr WD, Materials Science and Engineering - An introduction, third edition, Jhon Willey \& sons, New York, 1994.

2 Canevarolo Jr SV. Ciência dos Polímeros, 2ª edição, Artiliber, São Paulo, 2006.

3 Allevato C, Ramos MA. Aplicações da Técnica de Emissão Acústica em Ensaios de Corrosão. Petrobras. RJ. 1980. pp. 258-265.

4 Miller RK. Nondestructive Testing Handbook - Volume Five, Acoust emission testing. Estados Unidos da América: American Society for Nondestructive Testing - ASNT. 1987

5 ABNT, NBR 15181 - Ensaios não destrutivos - Emissão Acústica - Terminologia, Associação Brasileira de Normas Técnicas - ABNT, São Paulo, Brasil, 2004. 